\title{
EXPERIENTIAL LEARNING AND THE ACQUISITION OF MANAGERIAL TACIT KNOWLEDGE
}

\author{
by \\ ${ }^{1}$ Steven J. Armstrong \\ $\&$ \\ Anis Mahmud \\ ${ }^{1}$ Address for correspondence: \\ Steve Armstrong \\ Centre for Management \& Organisational Learning \\ Hull University Business School \\ University of Hull \\ Hull, HU6 7RX \\ United Kingdom \\ Tel: 07813612028 \\ Fax: 01482463484 \\ email: s.j.armstrong@hull.ac.uk
}




\title{
EXPERIENTIAL LEARNING AND THE ACQUISITION OF MANAGERIAL TACIT KNOWLEDGE
}

\begin{abstract}
Tacit knowledge is believed to be one factor that distinguishes successful managers from others. This study sought to determine whether levels of accumulated managerial tacit knowledge (LAMTK) were associated with managers' dominant learning styles. Instruments used in the study, involving 356 Malaysian public sector employees, included Sternberg et al.'s (2000) Tacit Knowledge Inventory for Managers and a normative version of Kolb's (1999a) Learning Styles Inventory (LSI-III). Findings suggest that LAMTK is independent of the length of subjects' general work experience, but positively related to the amount of time spent working in a management context. Learning styles also had a significant relationship. Subjects who spent most of their time performing management functions and whose dominant learning styles were accommodating, had significantly higher LAMTK than those with different learning styles. There was also support for the belief that learners with a strong preference for all four different abilities defined in Kolb's learning theory may be critical for effective experiential learning.
\end{abstract}

Keywords: Experiential, Learning Styles, Tacit Knowledge 


\section{INTRODUCTION}

Drawing on Polanyi's (1966) distinction between tacit and explicit knowledge, it has been argued that the former may be one important factor distinguishing successful managers from others (Argyris, 1999; Wagner \& Sternberg, 1987). Not only has it been shown to be important for the success of individuals (Nestor-Baker, 1999; Wagner \& Sternberg, 1985), but it is also important for organizations (Baumard, 1999; Hall, 1993; Lubit, 2001; Prahalad \& Hamel, 1990). Tacit knowledge is believed to be a product of learning from experience that affects performance in real world settings (Nonaka \& Takeuchi, 1995; Sternberg \& Wagner, 1993). The nature of the relationship between tacit knowledge and experience has not been fully established, but it is possible that a range of individual differences such as intelligence, personality, prior knowledge, and psychological constructs such as cognitive style may have some impact on the knowledge acquisition process. A major objective of this study is to determine whether levels of accumulated managerial tacit knowledge (LAMTK) are related to managers' individual learning styles, and the degree to which their learning styles are consonant with the managerial context. It is a correlational study that uses Sternberg et al's (2000) Tacit Knowledge Inventory for Managers (TKIM) and Geiger et al's (1993) normative version of Kolb's (1999a) Learning Styles Inventory (LSI-III).

\section{Tacit Knowledge}

Our current understanding of the concept of tacit knowledge can be attributed to the work of authors such as Simon (1973), Neisser (1976), Schön (1983), Scribner (1986), Wagner \& Sternberg (1986), Janik (1988), Reber (1989), Nonaka \& Takeuchi (1995), Baumard (1999), Collins (2001), and von Krogh \& Roos (1995). The definition of tacit knowledge has been derived from several distinguishing characteristics. It is knowledge that people do not know 
they have (Forsythe et al., 1998), resisting articulation or introspection (Cooper \& Sawaf, 1996; Morgan, 1986). Although tacit knowledge may be considered by some to be a bane to articulation, others consider it to be measurable (e.g. Ceci \& Liker, 1986; Forsythe et al., 1998; Sternberg \& Grigorenko, 2001a). It cannot be understood through direct articulation, however, due to its tacit nature, but it must be inferred from actions and statements (Forsythe et al., 1998).

The origin of the construct is often attributed to the science philosopher, Michael Polanyi, who described it in his famous quote "we can know more than we can tell" (1966, p4), but Baumard (1999) traces its history back much further to the ancient Greeks in phronesis. He describes it as the result of experience that cannot easily be shared, as knowledge that is personal, profound, non-scientific and "generated in the intimacy of lived experience" (p 53). Such characteristics leave no doubt that tacit knowledge derives from experience (Nonaka, 1994) and analogical reasoning which forms intuitions and instincts (Hatsopoulos \& Hatsopoulos, 1999). For the purpose of this research, the definition of tacit knowledge will be taken to be 'knowledge that is grounded in personal experience, and is procedural rather than declarative in structure ${ }^{1}$ (Sternberg \& Horvath, 1999).

\section{Tacit Knowledge in the Professions}

There has been a substantial amount of research into the nature of tacit knowledge in a variety of professions such as nursing (Benner \& Tanner, 1987; Eraut, 1994; Herbig et al., 2001), education (Nestor-Baker \& Hoy, 2001; Minstrell, 1999; Leithwood \& Steinbach, 1995; Almeida, 1994), medicine (Cimino, 1999; Patel et al., 1999), and Law and Accounting

\footnotetext{
${ }^{1}$ Anderson (1983) distinguishes between procedural knowledge and declarative knowledge by referring to the former as knowledge about how to do something, and to the latter as knowledge about something. Declarative knowledge is consciously formed, controlled and articulable, while procedural knowledge is identified as unconscious with automatic learning which guides actions and decisions without being in our field of consciousness (Anderson, 1983; Reber \& Lewis, 1977).
} 
(Marchant \& Robinson, 1999; Tan \& Libby, 1997). These studies provide a valuable insight into the working of tacit knowledge in these various professions. Sternberg's work into the nature of tacit knowledge is particularly noteworthy (e.g. Sternberg et al., 1993; Sternberg et al., 2000; Sternberg \& Grigorenko, 2001b; Sternberg \& Wagner, 1993; Wagner \& Sternberg, 1986) because it provides a framework and a sound methodological basis from which tacit knowledge can be studied. These studies have resulted in the development of inventories specifically aimed at furthering our understanding of tacit knowledge across a range of professions.

In Wagner and Sternberg's (1985) study of the role of tacit knowledge in groups of business managers, psychologists and bank managers, it became clear that there were significant variations in the level and content of tacit knowledge within the groups. These variations are believed to exist because individuals go through their experiences differently, and at different points in time and context. In Wagner et al.'s (1999) study of tacit knowledge in the sales profession, a particularly notable finding was that there were significant differences between the expert salespeople and novices. Other studies have examined differences in tacit knowledge between expert and novice (Murphy \& Wright, 1984; Patel et al., 1999; Tan \& Libby, 1997) or successful and typical groups (Klemp \& McClelland, 1986; Nestor-Baker, 1999; Wagner \& Sternberg, 1987; Williams, 1991) and most have identified differences in tacit knowledge between them. No studies have identified reasons that account for these differences, however.

\section{Different ways of Learning from Experience and Acquiring Tacit Knowledge}

Nonaka (1994) argues that the generation and accumulation of tacit knowledge is determined by the 'variety' of an individual's experiences and the individual's commitment and 
involvement in the 'context' of the situation (pp.21-22). But these may be antecedents to learning, with the learning process itself representing the major source of differences between tacit knowledge accumulated by different people. A person's aptitude to learn may be yet another differentiating factor (Leithwood \& Steinbach, 1995; Wagner \& Sternberg 1987). Despite the "explicit recognition of individual variations in the ability to learn from experience" (Reuber et al., 1990, p.267), little has been done to understand the reasons for these variations and Colonia-Willner (1998) identified this as a particularly important area for future research in the field.

One explanation may arise from the fact that people have consistent individual differences in their preferred ways of organizing and processing information and experience. Such differences are often referred to as cognitive styles (Messick, 1976). Baumard (1999) also drew our attention to the importance of individuals' pre-established cognitive patterns that uniquely filter incoming information when acquiring new knowledge. Its influence can be observed through a model of tacit knowledge proposed by Sternberg et al. (2000) which involves the mental processes of encoding, storing and retrieving information from memory. This draws upon Tulving's (1972) work on the organization of memory in terms of episodic, semantic, and procedural memory. Procedural memory bears relevance to tacit knowledge because tacit knowledge is a subset of procedural knowledge. Figure 1 shows the three memories and the related paths of knowledge acquisition.

\section{Figure 1 about here}

According to Baumard (1999) managerial tacit knowledge is generated in the intimacy of lived experience and Sternberg et al (2000) regard it as a subset of procedural knowledge depicted by paths $\mathrm{A} 1$ or $\mathrm{C} 1$ in this model. This knowledge, unsupported by direct instruction, 
may well lead to a performance advantage for the individual because "it is likely that some individuals will fail to acquire it" (Sternberg et al., 2000, p.117). Again, there is only very limited understanding of why differences in the level and content of tacit knowledge occur across individuals who appear to have similar abilities and experiences (Hedlund et al., 2001; Sternberg et al., 1993; Sternberg \& Wagner, 1993; Wagner \& Sternberg, 1985). There is widespread evidence to suggest that this may be due to the different learning styles of individuals (Kolb \& Kolb, 2005; Kolb, 1984) because when learners are matched with environments that complement their unique learning styles, they achieve significantly higher learning outcomes (Nulty \& Barrett, 1996; Dunn \& Griggs, 2003). Learning style is believed to represent the interface between cognitive style and the external learning environment, and hence contextualises individual differences in learning (Sadler-Smith, 2001). Both theoretical (Curry, 1983) and empirical evidence has been put forward to support this assertion (Melear, 1989; Aragon, 1996).

Learning styles have been defined as peoples' consistent ways of responding to and using stimuli in the context of learning (Claxton \& Ralston, 1978). The concept evolved as an outgrowth of interests in cognitive styles (Jonassen \& Grabowski, 1993), defined by Messick (1984) as "characteristic self-consistencies in information processing that develop in congenial ways around underlying personality trends" (p. 61). Learning styles have been acknowledged as lying “... at the interface between abilities, on the one hand, and personality, on the other" (Sternberg \& Grigorenko, 2001b, p.2). This study explores the possibility that individual differences in learning styles may account for differences in levels of accumulated managerial tacit knowledge acquired through work-based experiential learning. 


\section{Experiential Learning Theory}

Experiential learning theory focuses on how managers acquire and transform new experiences and how these experiences lead to a greater sense of satisfaction, motivation, or development (Kayes, 2002). One notable model that is perhaps the most well-developed and wellresearched is Kolb's (1984) Experiential Learning Theory (ELT). The theory draws on the work of prominent scholars-notably John Dewey, Kurt Lewin, Jean Piaget, William James, Carl Jung, Paulo Freire, Carl Rogers and others- who gave experience a central role in their theories of human learning and development (Kolb \& Kolb, 2005). In this theory, experiential learning is defined as:

“...the process whereby knowledge is created through the transformation of experience. Knowledge results from the combination of grasping and transforming experience" (Kolb, 1984; p.41).

It is therefore explicit and definitional to the theory of Kolb that experience needs to be acted upon in order to be learned. Wight (1970, cited in Ekpenyong, 1999) suggests that people seldom learn from their experience unless that experience is examined as a means of providing meaning as he/she sees it. Through this process of examination, understanding, insights, and discoveries are made to add value to the particular experience as well as other prior experiences. This is then integrated into the person's "system of constructs which s/he imposes on the world through which s/he views, perceives, categorises, evaluates and seeks new experience" (Op-cit. pp. 234-282).

Kolb's four stage model of learning from experience is based on such a process (Figure 2) and focuses on the polar extremes of concrete-abstract and active-reflective dimensions of 
cognitive growth. The concrete-abstract dimension represents how one prefers to perceive the environment or grasp experiences in the world. The active-reflective dimension represents how one prefers to process incoming information and transform experience (Kolb, 1984). The model represents a four-stage cycle of learning from concrete experience (CE) leading to reflective observation (RO) on that experience followed by the development of theory through abstract conceptualization (AC). The theory is then tested through active experimentation (AE) which leads to new concrete experiences, and so the cycle continues.

\section{Figure 2 about here}

Possession of all four different abilities indicated by the four poles of the model was argued by Kolb and Fry (1975) to be critical for effective learning from experience. Not everyone, however, has the ability to be strong in all four modes and most people tend to develop particular strengths in one or two of these due to their hereditary equipment, past life experiences, and demands of their present environment (Kolb, 1984). This led to the development of learning styles to explain these phenomena. The two distinct dimensions of Concrete Experience-Abstract Conceptualization and Reflective Observation-Active Experimentation are orthogonal and form four quadrants that lead to different learning styles (Kolb, 1984). Divergers combine learning steps of concrete experience (CE) and reflective observation (RO). Assimilators combine the steps of reflective observation (RO) and abstract conceptualization (AC). Convergers combine the steps of abstract conceptualization (AC) and active experimentation (AE). Accommodators combine the learning steps of active experimentation (AE) and concrete experience (CE). Research and clinical observations (Kolb, 1984; 1999a; 1999b) led to a summary of the four basic learning styles. 
Divergers: - People with this orientation excel at viewing concrete situations from many perspectives and perform well in situations that call for generation of alternative ideas such as brainstorming. They are interested in people and tend to be imaginative and feeling-oriented. Educationally, Divergers have a tendancy to specialise in the Arts, History, Political Science, English and Psychology. With regard to professional career choice, social services, arts and communications professions tend to comprise people with divergent learning styles. This may be because they are more adept at establishing personal relationships, communicating effectively, helping other people, and sense making.

Assimilators: The strength of this orientation lies in inductive reasoning and the ability to create theoretical models. They are capable of understanding a wide range of information and putting it into concise logical form. They tend to be less focused on people and more concerned with ideas and abstract concepts. Educationally, individuals with Assimilating learning styles tend to specialise in Mathematics, Economics, Chemistry and Sociology. Professions in the areas of science, information, and research tend to draw people with assimilating learning styles and this may be because they are more adept at gathering and analysing information, theory building, and developing conceptual models.

Convergers: The greatest strength of this approach lies in problem solving, decision making and the practical application of ideas and theories. Individuals with this learning style prefer to deal with technical tasks and specific problems through hypothetical-deductive reasoning rather than with social and interpersonal issues. Educationally, convergers are drawn to abstract and applied subject areas like physical sciences and engineering. They tend to seek professional careers in the fields of technology, economics and environment science, 
preferring job roles oriented towards engineering that require technical and problem-solving skills like quantitative analysis and the use of technology.

Accommodators: The strength of people with this orientation lies in doing things, in carrying out plans and tasks, and getting involved in new experiences. They prefer to solve problems in a trial-and-error manner relying on their own intuition or other people for information, rather than their own analytic ability. This style is important for effectiveness in action oriented careers where one must adapt oneself to changing circumstances. Individuals with accommodating styles frequently have educational backgrounds in Business and Management. They tend to pursue careers in organizations (e.g. management, public finance, educational administration) and business (e.g. marketing, government, human resources etc) where they can bring to bear their competencies in Acting skills: Leadership, Initiative, and Action (Kolb, Boyatzis \& Mainemelis, 2000).

The principal characteristics of these four styles led to Kolb's (1984) assertion that matching learning context and learning style will lead to enhanced learning performance. Empirical evidence has been found for this matching hypothesis (Hayes \& Allinson, 1996) demonstrating not only improved learning achievement (Sein \& Bostrom, 1989) but also that satisfaction with learning will be enhanced (Vondrell \& Sweeney, 1989; Hudak, 1985). Such improvements in the context of experiential learning are likely to lead to concomitant increases in levels of tacit knowledge, believed to be one important factor accounting for career success (Wagner \& Sternberg, 1987). Conversely, a mis-match between learning style and learning context is likely to impede the process of learning and knowledge acquisition in a specialised profession. Someone with a strong orientation towards the assimilator style, for example, would tend to be less focused on people and more concerned with developing new 
theories and conceptual models. They would therefore be less suited to an action oriented context such as management because learning opportunities in this context would be congruent with the Accommodator learning style.

\section{HYPOTHESES}

Previous research has shown that levels of tacit knowledge are higher in expert/successful groups than novice/trainee or typical groups of managers (Wagner \& Sternberg, 1987; Klemp \& McClelland, 1986; Williams, 1991). These expert-novice comparison studies have been replicated in other groups of professionals such as Psychologists (Wagner \& Sternberg, 1985), Sales Professionals (Wagner et al, 1999), Bank Managers (Wagner \& Sternberg, 1985), Public School Superintendents (Nestor-Baker, 1999) and medicine (Patel et al, 1999). Those studies were conducted in western cultures and few have attempted to replicate these studies across cultures although Sternberg \& Grigorenko (2001a) suggest that such studies would likely yield similar results. In this study it is therefore hypothesised that:

Hypothesis 1: Successful managers within the Malaysian Public Sector will have accumulated significantly higher levels of managerial tacit knowledge than either novice/trainee or typical managerial groups within that sector.

The reasons why significant variations in tacit knowledge exist within groups of managers and why these 'differences in tacit knowledge are consequential for career performance in professional and managerial career pursuits' (Wagner \& Sternberg, 1985, p452) requires further investigation. According to Scribner (1986) those that are regarded to be successful and relative experts rely on a well developed repertoire when responding to problems in their respective domains. They draw on their tacit knowledge which is context specific knowledge 
about what to do in a given situation, or class of situations (Sternberg \& Grigorenko, 2001b). Tacit knowledge is gained primarily from working on practical, everyday problems specific to their particular domain (Borman et al, 1993). The consequence of drawing on, and using ones tacit knowledge is also likely to be context-dependent (Choo, 1998; Sternberg \& Grigorenko, 2001a) because tacit knowledge does not always transfer effectively from one professional context to another (Serpell, 2000; Ceci \& Roazzi, 1994). To be useful, it needs to be relevant. To explore context dependency in this study, subjects were differentiated according to whether they had spent most of their working careers performing functions and duties that were predominantly of a management nature involving them in managing such things as human, financial and materials oriented organizational resources. Subjects in the present study who spent most of their working careers in a context that was significantly less managerial in nature included professionals such as engineers or accountants who had spent most of their previous careers performing technical or other non managerial work. Similar methods were adopted by Wagner (1987) and Wagner et al (1999). This leads to our second hypothesis:

Hypothesis 2: Subjects working in a predominantly managerial context will have higher levels of managerial tacit knowledge than those employees whose work experiences were based within contexts that were significantly less managerial in nature.

Learning is concerned with the production of knowledge (Kolb, 1984) and according to Jarvis (1987) Kolb's theory has successfully demonstrated an intimate relationship between the two terms. If matching learning style and context produces ideal learning through improved learning achievement (Kolb, 1984; Sein \& Bostrom, 1989) and enhanced satisfaction with learning (Hudak, 1985), then it is reasonable to assume that this will lead to increased levels 
of tacit knowledge. Since the present study is concerned specifically with 'managerial' tacit knowledge and because the accommodator learning style is deemed to be consonant with learning in the management profession (Kolb, 1999b) it is further hypothesised that:

Hypothesis 3a: Subjects with accommodating learning styles working in a predominantly management context will have higher levels of managerial tacit knowledge than other subjects in the study.

Hypothesis 3b: Of the subjects working in a predominantly management context, those with accommodating learning styles will have higher levels of managerial tacit knowledge than subjects with each of the other three cardinal learning styles.

Kolb and Fry (1975) argued that the possession of all four different abilities or learning modes (Concrete Experience, Abstract Conceptualization, Reflective Observation and Active Experimentation) indicated by the four poles of Kolb's (1984) model were critical for effective learning from experience. Unfortunately, there has been a dearth of studies in this area due to limitations imposed by the ipsative nature of the Learning Styles Inventory. The use of a normative version of the LSI adopted in this research, however, permits such an analysis. It is therefore hypothesised that:

Hypothesis 4: Subjects with higher scores on all four learning abilities/modes of Kolb's (1984) model will possess higher levels of managerial tacit knowledge than those with low scores on the four poles of the model. 


\section{METHOD}

\section{Population}

The population of interest were employees of the Malaysian Public Sector, which is made up of nineteen different services. The Administrative and Diplomatic Service (ADS) is at the pinnacle of the sector, providing management, leadership, and administration in areas of decision making, policy formulation, program planning, control of resources, and programme coordination and implementation (Fauziah, 1980). Other services provide both professional and technical expertise, such as medical, accountancy, engineering, education $\&$ police. There are also lower levels of support services that provide assistance to these two main cadres of administrative/management and technical/professional groups.

\section{Sample}

The sampling frame comprised 1120 staff from the Malaysian Public Sector who attended training courses, workshops, talks and seminars at INTAN, which is part of the Malaysian National Institute of Public Administration, between July and October 2003. INTAN is the nation's premier public service training institution with its niche in providing development programmes and leadership training for both managers and potential managers in the public service (Malek Shah, 2003).

Subjects in the study came from all nineteen services within the sector, although the majority (approx. 60\%) were from the Administrative and Diplomatic Service. Their technical and professional expertise was wide ranging, as were their levels of work experience. Most subjects had been selected to attend these courses because they already carried out work that was predominantly managerial in context, or because they had been identified as having management potential. 
Questionnaires were returned by 356 subjects, representing an overall response rate of $32 \%$. Of these, 113 (32\%) were classified as novice/trainee, 206 (58\%) were classified as typical, and $37(10 \%)$ were classified as expert/successful. The novice/trainee group comprised employees with less than one year's working experience, whereas the typical group comprised employees whose experience ranged from 2 - 32 years, and averaged 9.4 years. Table 1 provides descriptive statistics of levels of experience for the novice, typical and successful groups.

\section{Table 1 about here}

The group of expert/successful managers were needed to create a profile against which the other two groups could be compared. This is a fundamental requirement of the Tacit Knowledge Inventory for Managers (TKIM) used in the study. The prototypical scoring system $^{2}$ of the TKIM requires scores from the novice group and the typical group to be compared against the scores of the expert/successful managers' profile. Subjects with TKIM scores close to the scores of the expert/successful profile are deemed to have a higher level of managerial tacit knowledge.

\section{Criteria for Selecting the Expert/Successful Manager Group}

Previous studies of tacit knowledge in the professions have identified successful managers as those who are senior, highly successful and very experienced managers, often irrespective of the work context (e.g. Kerr, 1991; Klemp and McClelland, 1986; Wagner and Sternberg,

\footnotetext{
${ }^{2}$ Wagner (1987) used the term 'prototype' to describe the quantification of tacit knowledge by "comparing a subject's response item ratings to a prototype derived from the mean response-item ratings of an expert group" (p.1240). The term prototype therefore refers to a mean rating of the expert group, and not a trial method for scoring the TKIM.
} 
1987; Williams, 1991). However, evidence from the literature has shown that tacit knowledge is context-specific (Nonaka, 1994; Sternberg \& Grigorenko, 2001a) and has a certain life span (Argyris, 1999). In other words, tacit knowledge which brought success to individuals within a given work context, may not be a suitable indicator of successful management in a different contexts or in a different timeframe. Nor is tacit knowledge necessarily dependent on the length of general work experience (Colonier-Willner, 1998).

The present study therefore builds on, and extends the selection criteria for successful management used in previous studies. It does this by considering only those who stand out as being successful within the same work context as the subjects being studied (i.e. within the Malaysian Public Sector), and within a limited frame of time. Another major criteria was that they must have received a highly prestigious service excellence award for management in the past three years. Candidates in receipt of such an award undergo a rigorous selection process based on the following criteria:

* A candidate must be nominated by their superior as being an exemplary manager.

* A candidate must have received a score of greater than $90 \%$ for each of the last 3 years on their annual appraisal form designed to measure overall management success.

* Nominated candidates are rigorously assessed by a selection committee comprising senior staff in the organisation, including the respondent's senior departmental manager.

The number of awards never exceeds $5 \%$ of the population under the purview of each awarding committee. A service excellence award can be awarded again to the same people provided the rigorous selection procedures continue to be met. Consequently, managers currently holding this award are deemed to be among the most expert and successful in the organisation. Information about individuals' service excellence awards was collected in the research questionnaire. Supporting evidence was also collected from respondents' departments. 


\section{Measures}

Tacit Knowledge - Wagner and Sternberg's (1985) Tacit Knowledge Inventory for Managers (TKIM) was administered to all subjects in order to determine LAMTK. A brief explanation, together with sample items for the TKIM are given in Appendix A together with the scoring regime. Theoretically, expert/successful managers are expected to respond differently to novices due to the content and organization of their tacit knowledge (Wagner et al., 1999). The majority of previous studies have focussed on comparing the responses of different groups of people such as business students and business managers to scenarios depicted in the TKIM against scores obtained from a successful group (e.g. business experts) within that particular field, referred to as the "expert-novice comparison".

Learning Style - A normative version of Kolb's (1999a) Learning Styles Inventory (LSI), was also administered to all subjects in the study. Kolb's standard LSI consists of learning situations that are presented in twelve statements and respondents are expected to rank-order four sentence endings that correspond to four learning styles against each statement. The LSI is based on an ipsative scale and the justification for this lies in the need to maximize differences within the measure (Geiger et al., 1993) because the LSI is intended to measure an individual's preference in learning, rather than ability to learn. However, criticisms of some of the previous studies using the LSI have been levelled at the deficiency and limitations of ipsative measures. Ipsative measures produce nominal data and previous researchers have often proceeded to correlate these scores with normative data. This is known to be controversial (Higgs, 2001) and limits the nature of the methods that can be used to determine an instrument's validity, and compare it with other instruments (Baron, 1996; Bartram, 1996). Correlational studies using ipsative measures with other nominal variables are permissible but require each cell to have a minimum of five observations per cell for a chi-square test, thereby 
necessitating large sample sizes (Norusis, 1994). Attempts to create and study a normative form of the LSI were first undertaken by Romero et al. (1992) and Geiger et al. (1993).

Geiger et al. (1993) converted the 12 items (with four endings) on the LSI into an independent, randomly ordered 48-item questionnaire. Each item was scored on a 7-point Likert scale. For example, the item from Kolb's original LSI shown below, which respondents normally rank order from 1 to 4 ,

I learn best from,

$\begin{array}{ll}\text { a chance to try out and practice } & \text { personal relationships } \\ \text { observation } & \text { rational theories }\end{array}$

was transformed into four items using 7-point Likert scales as follows:

$$
\begin{array}{ll}
\text { Not } & \text { Very mисh } \\
\text { like me (1) } & \text { like me (7) }
\end{array}
$$

1. I learn best from personal relationships

2. I learn best from a chance to try out and practice

3. I learn best from observation

4. I learn best from rational theories

Statistical procedures in several previous studies to compare the ipsative and normative forms of the LSI revealed strong support for the same learning style preferences theorised by Kolb in both measures. Consistent and strong reliabilities for the randomized normative version were also noted ${ }^{3}$. Due to the nature of the present study, a normative version of the LSI was therefore adopted. The scoring regime can be found in Appendix B.

\footnotetext{
${ }^{3}$ Geiger et al. (1993) reported reliability coefficients for the normative version of the LSI ( 0.83 for CE, 0.77 for RO, 0.86 for AC and 0.84 for AE) as being "very similar to those obtained by the ipsative version" (p.721). Similar findings were also reported by Merritt and Marshall (1984) and Mahmud (2006).
} 
Management Context - The context of subjects' work environment was determined by examining whether or not their working time had been spent predominantly performing managerial or non-managerial functions. These data were collected using self-developed items within the demographic section of the survey instrument where respondents were asked to list their current and previous job titles. They were also asked to indicate the period of time they performed each job and whether or not these jobs were predominantly managerial in nature. The item, as it appeared in the survey instrument, is shown below. Briefing sessions were held with all subjects in the study to impress on them that this part of the survey was concerned specifically with managerial functions involving the management of human as well as other resources such as finance and/or materials. Subjects were encouraged to approach the researchers if there were any doubts about these items. In almost every case the distinction was very clear because item responses indicated whether they were actually managers or other professionals such as engineers or accountants in the early stages of a transition into the field of management. In the few cases where there were any doubts subjects were interviewed in order to clarify the situation and to make an appropriate judgement. Such a case might include someone who appeared to be involved in engineering research activities but had few if any direct line subordinates.

\begin{tabular}{|c|c|c|c|c|}
\hline \multirow[t]{2}{*}{ Current Job Title } & \multicolumn{2}{|c|}{$\begin{array}{c}\text { Job Category } \\
\text { (mark } \sqrt{ } \text { in the respective boxes) }\end{array}$} & \multicolumn{2}{|c|}{$\begin{array}{l}\text { Period in this } \\
\text { position }\end{array}$} \\
\hline & Managerial & Non-managerial & Years & Months \\
\hline & $\square$ & $\square$ & & \\
\hline \multirow[t]{2}{*}{ Previous Job Title } & Managerial & Non-managerial & \multicolumn{2}{|c|}{$\begin{array}{l}\text { Period in this } \\
\text { position }\end{array}$} \\
\hline & & & Years & Months \\
\hline & $\square$ & $\square$ & & \\
\hline & $\square$ & $\square$ & & \\
\hline & $\square$ & $\square$ & & \\
\hline & $\square$ & $\square$ & & \\
\hline & $\square$ & $\square$ & & \\
\hline
\end{tabular}


Other Demographic Variables - A number of other demographic variables were included in the study such as respondent's age, number of staff under their supervision, number of years of work experience, and educational level $(1=\mathrm{PhD}$; 2=Masters Degree; 3=Bachelor's Degree; 4=Diploma; 5=Other).

\section{ANALYSIS AND RESULTS}

TKIM scores for the expert/successful group were tabulated and values for each variable were calculated to form the expert/successful managers' profile. The standard deviations are consistent with findings of previous research where it was concluded that there was an acceptable level of agreement among the expert/successful group (Forsythe et al., 1998).

Scores for subjects in the novice and typical groups were calculated using the method of scoring discussed in Appendix A. This procedure gives rise to a score for the level of managerial tacit knowledge for every respondent compared with the expert/successful managers' profile. It should be noted that scores are expected to decrease rather than increase with advancing levels of tacit knowledge because these scores represent deviations from the expert/successful group. The closer the pattern of responses to the successful group, the lower the score (Wagner, 1987). The relative level of managerial tacit knowledge ranged from between 0.67 and 1.84 for the entire 319 cases. Despite the small range of scores obtained, this is entirely typical of the TKIM scoring system that reflects the differences in scores of novice and typical groups against an expert/successful group (Sternberg \& Grigorenko, 2001a). 
Internal consistency reliability estimates for the two inventories used in the research are shown in Table 2. The moderately high internal consistency reliabilities for the normative version of the LSI indicates that what the scale measured was being measured relatively consistently across all items. Internal consistency reliability for the Tacit Knowledge Inventory for Managers was acceptable for the total overall score. The reliability of the individual tacit knowledge sub-scales were somewhat lower, ranging from .51 to .58 . This is consistent with previous studies that have reported total score reliabilities of .79 (Wagner, 1987), and .68 (Wagner \& Sternberg, 1985) and tacit knowledge sub-scales reliabilities ranging from .48 to .90 (Wagner, 1987). Only scores for the full scale of the TKIM were used in testing hypotheses in the present study so there is no concern over the low alpha levels for the sub-scales.

\section{Table 2 about here}

A correlation matrix of measures used in the study showing means, standard deviations, and reliabilities can be found in Appendix C.

\section{Hypothesis 1: Successful managers will have accumulated significantly higher LAMTK than other groups of employees within a related work context.}

To test for a previously reported phenomenon that successful-novice groups within the same professional context differ in levels of accumulated tacit knowledge (e.g. Nestor-Baker, 1999; Patel et al., 1999) a comparison was made between the successful group and the novice and typical groups defined above. The mean scores on LAMTK for each of the three groups are 
shown in Table 3. Again, the small range of scores in the table reflects the prototype-based scoring system used in the TKIM that measures differences in scores of novice and typical groups compared with the successful group. One-way analysis of variance $(\mathrm{F}=5.37, d f=2$, $p=.005)$ and Duncan multiple-range tests indicate that the novice group had significantly lower LAMTK than the successful manager group. Whilst it can be seen from Table 3 that the successful manager group also had higher levels of LAMTK than the typical group, the difference was not significant. Hypothesis 1 is therefore only partially supported.

\section{Table 3 about here}

\section{Hypothesis 2: Relationship between LAMTK and exposure to managerial functions}

In order to test whether subjects working in a predominantly managerial context had a higher LAMTK than those whose work experiences were based in contexts that were significantly less managerial in nature $(\mathrm{H} 2)$, it was necessary to remove the novice/trainee group $(<1$ year work experience) from the analysis because they would clearly not have gathered relevant contextual experience. An independent samples t-test revealed that subjects working in a predominantly management context possessed higher LAMTK $(\mathrm{M}=.874, \mathrm{sd}=0.10, \mathrm{n}=82)$ than others $(\mathrm{M}=.906, \mathrm{sd}=0.12, \mathrm{n}=124)$. This result was found to be significant $(\mathrm{t}=-2.0, \mathrm{p}$ $=0.02$, 1-tailed) and Hypothesis 2 is therefore supported.

\section{Hypothesis 3(a\&b): Relationship between LAMTK and Managers with Accommodating}

\section{Learning Styles}

Hypotheses 3a \& b involved two independent variables; 'learning styles' and 'managerial context'. A two-way ANOVA was therefore performed to determine possible interaction between these variables. 


\section{Table 4 about here}

Table 4 shows that the main effects of learning styles are significant whereas managerial context is not. However, the two-way interaction between learning styles and managerial context is significant $(\mathrm{F}=2.85, d f=3, p<.037)$. Therefore, whilst learning styles is significantly related to LAMTK, this needs to be considered to be a joint interaction with managerial context.

That considered, we will now test the hypothesis that subjects with accommodating learning styles who work in a predominantly management context will have a higher LAMTK than other subjects in the study (H3a). In order to do this, the sample was divided into two groups. The first group, which represented those whose working time was spent performing managerial functions, and whose dominant learning style was accommodating, achieved higher LAMTK $(\mathrm{M}=.869 \mathrm{sd}=0.079, n=43)$ than the remaining subjects $(\mathrm{M}=.918, \mathrm{sd}=$ $0.15, n=276)$. An independent samples t-test revealed that this difference was statistically significant $(\mathrm{t}=-3.19, \mathrm{p}=.001,1$-tailed). Hypothesis $3 \mathrm{a}$ is therefore supported.

In order to test whether subjects working within a predominantly management context, whose learning styles are accommodating, have higher LAMTK than subjects from each of the other three cardinal learning styles (H3b) the mean scores on LAMTK for each of the four styles are presented in Table 5. One-way analysis of variance $(\mathrm{F}=4.21, d f=3, p=.007)$ and Duncan multiple-range tests indicate that the accommodators had significantly higher LAMTK than both divergers and assimilators. Whilst it can be seen from Table 5 that accommodators also 
have higher LAMTK than convergers, this difference was not significant. Hypothesis $3 \mathrm{~b}$ is therefore partially supported.

\section{Table 5 about here}

\section{Hypothesis 4: Relationship between LAMTK and scores on all four of Kolb's learning}

\section{abilities}

A Pearson correlation ${ }^{4}$ revealed a highly significant, though weak, relationship between the sum of the scores for all four LSI learning modes and LAMTK $(r=-0.183, n=319, p=.001)$, which lends partial support for Hypothesis 4. In order to test Kolb and Fry's (1975) assertion that the possession of all four different learning modes is critical for effective learning from experience, subjects were sorted according to their scores on the four points of the experiential learning model, $\mathrm{CE}, \mathrm{AC}, \mathrm{AE}$ and RO. Subjects whose magnitude of scores was in the upper quartile on all four points were regarded as the most robust learners. Subjects who scored lowest on all four points were expected to have a significantly lower LAMTK than those in the upper most quartiles. Remaining subjects were grouped together to represent the middle two quartiles.

\section{Table 6 about here}

Table 6 shows the descriptive statistics for values of LAMTK for each of the three groups. One-way analysis of variance $(F=8.45, p=0.000)$ indicated that there were significant differences between the groups. Post-hoc comparisons using Duncan multiple range tests confirmed that subjects in the upper most quartile have significantly higher LAMTK than

\footnotetext{
${ }^{4}$ As noted earlier in the article, TKIM scores are expected to decrease rather than increase with advancing levels of tacit knowledge which is why the correlation is negative.
} 
those in the lowest quartile. This result provides support for the hypothesis that subjects who scored high on all four learning abilities/modes of Kolb's (1984) model will possess a higher LAMTK than those who scored lowest on all four learning abilities/modes.

\section{Other Findings}

Understanding of why differences in tacit knowledge occur across individuals who seem to have similar abilities and experiences is limited (Hedlund et al, 2001). Whilst the role of experience in the acquisition of tacit knowledge remains undisputed (Nonaka \& Takeuchi, 1995; Sternberg \& Wagner, 1986), studies of the relationship between them have revealed mixed results (Colonia-Willner, 1998; Wagner, 1987; Wagner \& Sternberg, 1985). It has been argued that what actually matters is not the length of general work experience but how people learn from their experiences (Colonia-Willner, 1998; Leithwood \& Steinbach, 1995). Experience needs to be properly acted upon to be learned (Wight, 1970 cited in Ekpenyong, 1999). Whilst some studies have suggested that there may be a relationship between tacit knowledge and length of experience, correlations tend to be only weak to moderate (Wagner at al, 1999). Other studies have even revealed that significant variations in levels of tacit knowledge sometimes occur across individuals who have similar lengths of work experiences (Sternberg et al. 1993). This relationship was explored in the present study.

A correlation analysis revealed no significant relationship between length of general work experience and levels of accumulated managerial tacit knowledge $(r=-0.061, n=319$, $\mathrm{p}>0.276$ ) for the whole group of subjects. Nor were there statistically significant correlations between length of general experience and LAMTK when the group was divided into the typical $(\mathrm{r}=0.054, \mathrm{n}=206, \mathrm{p}>0.443)$ and novice groups $(\mathrm{r}=-0.054, \mathrm{n}=113, \mathrm{p}>0.568)$. 


\section{DISCUSSION}

Tacit knowledge is closely associated with experts and successful people (Nestor-Baker \& Hoy, 2001; Wagner \& Sternberg, 1985). There have been a plethora of well documented accounts of why tacit knowledge holds such value for both individuals and organizations alike (Baumard, 1999; Davenport \& Prusak, 1998; Sternberg et al., 1995) but there has been a dearth of empirical studies that attempt to identify and measure it (Busch \& Richards, 2000). Notable exceptions include the work of Wagner \& Sternberg (1985), and Dervin (1992) who developed instruments and techniques to measure the construct. Subsequent research led to the major finding that significant variations exist in the level and content of tacit knowledge within equivalent groups (Wagner \& Sternberg, 1985). This may be due to variations in the way individuals pass through their experiences at different points in time and context (Wagner et al., 1999), or a person's aptitude to learn may be a major factor accounting for these differences (Leithwood \& Steinbach, 1995). The present study has demonstrated that the nature of subjects' work experiences and their individual learning styles may also be significant factors accounting for these differences.

The study hypothesised that levels of managerial tacit knowledge will be higher in successful/expert managers than other groups of managers. It was further hypothesised that, irrespective of length of general work experience, managers who engage in a context that is dominated by managerial functions will accumulate more managerial tacit knowledge than others. Finally, it was hypothesised that these managers will learn from those experiences in different ways due to varying degrees of congruence/incongruence between the learning context and their individual learning styles. 
Results of the study revealed a significant difference in levels of accumulated managerial tacit knowledge (LAMTK) between successful and novice groups, which is entirely consistent with previous research in the field (Patel et al., 1999; Williams, 1991) and, in part, confirms the validity of the present study. The study also revealed that LAMTK is unrelated to the length of a person's general work experience. This important finding lends support to the belief that it may be how people learn from experience rather than the length of experience that matters (Hedlund et al., 2001).

The nature of subjects' work experience was found to be particularly important in the present study because those who spent substantially more time working in other professional contexts were found to have accumulated significantly lower levels of LAMTK than those who spent the majority of their time working specifically in a management context. This finding supports the views of Sternberg \& Grigorenko (2001a) and Choo (1998) that tacit knowledge is likely to be context-dependent. Within any profession, an individual's work environment will have a significant influence on levels of accumulated tacit knowledge, and these levels are likely to be moderated by the degree to which there is congruence between the job content and the work context.

An increasing amount of literature is now linking various forms of learning styles to tacit knowledge (e.g. Mahmud et al., 2004; Hempen, 2002; Meyer, 2003) and the present study showed evidence that subjects' learning styles were associated with LAMTK. A particularly significant finding was that the relationship between learning styles and LAMTK is interwoven with the context of managerial work. This finding is associated with Kolb's (1984) assertion that certain learning styles gravitate towards certain contexts and career types. For example, he suggested that the management profession is likely to be consonant 
with accommodating learning styles (Kolb, 1981) because people with this style tend to be more adept at dealing with people, exploiting opportunities and influencing others.

Outcomes of the present study lend support for this assertion because subjects who performed predominantly managerial functions, and whose dominant learning styles were accommodating, achieved significantly higher LAMTK than other subjects in the study. Whilst this is particularly noteworthy, it should perhaps come as no surprise when one considers that accommodators are likely to excel at learning tasks that: lack structure; require a commitment to objectives; depend on seeking and exploiting opportunities; depend on the need to influence and lead others; require both personal involvement and skills for dealing with people (Jonassen \& Grabowski, 1993). Kolb \& Fry (1975) also found that in an experiential learning environment, accommodators value a lack of structure, and a high amount of peer interaction. These factors are closely associated with characteristics one would expect to identify in managers of human resources, particularly when compared with subjects whose learning styles are dialectically opposite to accommodators in Kolb's model (e.g. assimilators). According to Jonassen \& Grabowski (1993) assimilators are more likely to excel at learning tasks that: require careful organising of information; depend on the building of conceptual models; require testing of theories and ideas; benefit from the design of experiments and analyses of quantitative data. Subjects with a dominant preference for these types of tasks would be more adept at responding to learning situations that involve data processing, or computer programming for example, but not for learning situations that lack structure and demand the influencing and leading of others, and where there is little time for reflective observation.

When responding to a particular learning situation, the learner is forced to select a mode of dealing with the incoming information. If the respondent's preferred learning style matches 
the learning situation then it is expected that the learning experience will be more effective and efficient (Katz, 1990) and that learning performance will be enhanced (Robey \& Taggart, 1981). When responding to a variety of different learning situations encountered in experiental learning, however, one would expect that the possession of all four learning modes of Kolb's (1984) model would be critical for effective learning from experience (Kolb \& Fry, 1975). Robust learners scoring highly on all four learning modes might be expected to respond more effectively to a variety of different learning situations than those scoring lower on all four modes. Because learning is believed to be the process whereby knowledge is created through the transformation of experience (Kolb, 1984, p38) one would therefore expect robust learners to have higher levels of LAMTK. Results from the present study found support for this argument because subjects who scored high on all four of the cardinal learning styles were found to possess higher LAMTK than those who scored lowest on all four learning modes.

\section{CONCLUSIONS AND IMPLICATIONS}

The nature of the relationship between experience and the acquisition of tacit knowledge has never been fully established. Furthermore, there is only very limited understanding of why differences in level and content of tacit knowledge occur across individuals who appear to have similar abilities. The results of this study have provided further evidence that tacit knowledge is independent of the length of peoples general work experience, but closely associated with matching work functions to the work context. Results also suggest that tacit knowledge acquired through experiential learning may be influenced by managers' individual learning styles, and the degree to which these are consonant with the work context. Outcomes of the study have a range of implications for theory, management education, management development, and future research in these areas as follows. 
Most previous empirical research associated with managerial tacit knowledge has focused on building new theory about its role in predicting performance (Argyris, 1999; Forsythe et al, 1998). There has been a dearth of studies that address reasons for individual variations in the ability to learn from experience (Reuber et al, 1990). Colonier-Willner (1998) identified this as a particularly important area of future research, especially reasons why expert managers acquire more tacit knowledge than others even though their intellectual abilities and general work experiences may sometimes be similar. The present study has demonstrated that learning styles provide one explanation and may be a particularly fertile area for future investigation. Some ideas for further research are discussed below. Commensurate with this study, future ones should consider using a normative version of the Learning Styles Inventory due to limitations of the ipsative version highlighted earlier. The inventory used in this study allowed both the dominant style, and strength of preference for each style to be measured without compromising the psychometric properties underlying Kolb's experiential learning theory.

With regard to management education, an important question that needs to be addressed is how to facilitate the acquisition of managerial tacit knowledge if this is one of the most important factors distinguishing successful managers from others? Evidence suggests that most learning to manage occurs on the job (Cunningham \& Dawes 1997) in tacit, culturally embedded ways through peoples' work practices within organizations. How then, can management educators substitute for such learning when formal education programs continue to separate learning from practice? One way is to blend formal approaches with informal learning that takes place in work-based problem scenarios. Service learning approaches (Kenworthy-U'Ren \& Peterson, 2005) designed to shift the emphasis from didactic learning 
in a classroom to learning through participation in social practice in the workplace is one example of where real world problems and real world needs are dealt with in the context of learning. A wide variety of action learning approaches are also available (Raelin, 1999) where problems are used as a stimulus and focus for student activity (Boud \& Feletti, 1991). On the basis that the present study confirmed the context dependent nature of tacit knowledge (Gottfredson, 2003; Choo, 1998) these approaches may benefit from more deliberate attempts to closely match learning experiences with situations that are consonant with the specific management context being considered. Such approaches would increase the probability of developing what Schon (1991) described as ‘honed intuition' or what Fukami (2007) referred to as 'practical wisdom'. This derives from her discussion of three knowledge types associated with organizational wisdom where she referred to 'episteme' as being theoretical knowledge of the sort typically dispensed in the classroom, 'techne' as the knowledge of making, associated with a craftsperson, and 'phronesis' which is thought of as 'practical wisdom'. She described the latter as "the ability to interpret and adapt knowledge to a particular context, situation, or problem" (p4). This has close connotations with tacit knowledge referred to in this article.

The present study also demonstrated that a consideration of learning styles may be beneficial in facilitating learning in a management development context. Levels of managerial tacit knowledge were higher when subjects' learning styles were matched with discipline demands and lower among those whose learning styles were incongruent with their discipline norms. In relation to management training this may explain why people with similar abilities experience more learning difficulties than others. This opens up the possibility suggested by Rush \& Moore (1991) of restructuring training and modifying instructional treatments and strategies as a means of addressing individual learner differences. 
An interesting alternative to matching training to the styles of the trainee would be to expose learners to a mis-matched learning environment in order to help them develop a wider repertoire of coping behaviours and learning strategies. Those that can learn to use a variety of problem solving and learning strategies, and apply them in situations that do not match with their natural learning style, "may be more able to perform effectively across a wider range of situations than employees who have limited stylistic versatility" (Hayes \& Allinson, 1996, p71). Kolb (1984) also acknowledged the potential longer term value of intentionally mismatching to increase adaptability, help learners overcome weaknesses in their learning style, and develop a more integrated approach to learning. The viability of this depends to some extent on whether learning styles are stable or open to change. Recent thinking in this area suggests that unlike cognitive personality styles, learning styles can be modified to a degree through learning and training strategies (Armstrong, 2006; Curry, 2000).

Increasing learner adaptability was identified by Kolb et al (2000) as an important new direction in experiential learning theory. They suggest a move from research that examines conditions of extreme learning specialisation to empirical testing of a theoretical proposition with regard to integrated learning. This is conceptualized as "an idealized learning cycle or spiral where the learner 'touches all the bases' - experiencing, reflecting, thinking, and acting - in a recursive process that is responsive to the learning situation and what is being learned" (Op-cit, p22). They refer to three orders of learning styles. The first refers to the specialised learning styles of Diverging, Assimilating, Converging and Accommodating. Second order learning styles represent learning orientations that combine the abilities of two basic learning styles. They present the concept of the 'Northener' learning style which combines the characteristics and abilities of the Diverging and Accommodating basic styles referred to in 
Figure 2. The 'Easterner' learning style combines the characteristics and abilities of the Diverging and Assimilator basic styles. The 'Southerner' learning style combines elements from the Assimilating and Converging basic styles and the 'Westerner' learning style combines those of the Converging and Accommodating basic styles. Third order learning styles refer to balanced learning profiles where people learn in a holistic manner utilising the abilities associated with all four learning modes. There is very little understanding of these second and third order styles according to Kolb et al (2000) who say that more research about balanced learning profiles is urgently needed. The present study partly considered balanced learning styles through hypothesis 4 , the results of which showed that subjects who scored high on all four learning modes possessed higher LAMTK. Clearly there is scope for more detailed research in this area, particularly research that explores the links between second/third order learning styles and managerial tacit knowledge.

Future research is also needed to identify other variables that mediate the acquisition of tacit knowledge. Understanding the role of informal learning, especially the unplanned and unintentional learning that occurs during a manager's development (Mahmud, 2006) is still in its infancy and would also benefit from more systematic empirical research to build on current theory. Empirical studies of the interaction between implicit and explicit knowledge and the mechanisms by which they are intertwined would also lead to further advancements in our ability to develop managers to their full capacity.

The present study has made a unique contribution to our understanding of the acquisition of managerial tacit knowledge. Not only has it demonstrated that learning styles may be a significant factor accounting for differences in levels of managerial tacit knowledge but the study has also shown that the degree to which job content and work context are congruent is 
also an important factor. The study also demonstrated that managerial tacit knowledge is positively related to time spent working in a management context but is unrelated to the length of general work experience. The field of research exploring tacit knowledge in expert/novice groups in a variety of professions have been largely confined to western cultures. Another significant contribution of the present study is that the previously reported phenomenon that expert-novice groups within the same professional context differ in their levels of accumulated tacit knowledge has been extended to include the Malaysian Public Sector. Further studies of this type in a variety of other local and national contexts would be helpful in determining whether the present findings and implications can be accepted with confidence and generalised to other groups of managers. 


\section{REFERENCES}

Almeida, C.B. (1994). The Acquisition of Tacit Knowledge Through Cooperative Education (Internship). (Doctoral dissertation, Boston College). University Microfilms International Dissertation Services, AAT 9522385.

Anderson, J. (1983). The architecture of cognition. Cambridge, MA: Harvard University Press.

Aragon, S.R. (1996). The development of a conceptual framework of learning for native American adult learners in a formal educational environment. Unpublished Doctoral Dissertation, University of New Mexico.

Argyris, C. (1999). Tacit Knowledge and Management. In R. J. Sternberg \& J. A. Horvath (Eds.), Tacit knowledge in professional practice: researcher and practitioner perspectives. Mahwah, N.J.: L. Erlbaum.

Armstrong, S.J. (2006). Cognitive styles and learning styles: Origins and implications for teaching, learning and research in cross cultural contexts. In S. H. Ong, G. Apfelthaler, K. Hansen, N. Tapachai (Eds.), Intercultural Communication Competencies in Higher Education and Management, 2006, Singapore: Marshall Cavendish Academic. [ISBN: 981-210-461-5]

Baron, H. (1996). Strengths and Limitations of Ipsative Measurement. Journal of Occupational and Organizational Psychology, 69, 49-56.

Bartram, D. (1996). The Relationship between Ipsatized and Normative Measures of Personality. Journal of Occupational and Organizational Psychology, 69, 25-39.

Baumard, P. (1999). Tacit Knowledge in Organizations. London: Sage Publications.

Benner P. \& Tanner C. (1987). How expert nurses use intuition. American Journal of Nursing $1,23-31$.

Borman, W. C., Hanson, M. A., Oppler, S. H., \& Pulakos, E. D. (1993). Role of supervisory experience in supervisory performance. Journal of Applied Psychology, 78, 443-449.

Boud, G. and Feletti, G. (1991). The challenge of problem based learning. London: Kogan Page.

Busch, P. \& Richards, D. (2000). Measurement of articulable Tacit Knowledge using Formal Concept Analysis. Downloaded 2 September, 2002 from http://www.comp.mq.edu.au/ richards/papers/acis2000-3.PDF 
Ceci, S. \& Liker, J. (1986). Academic and non-academic intelligence: an experimental separation. In Sternberg, R. \& Wagner, R. (Eds.). Practical intelligence: Nature and origins of competence in the everyday world. New York: Cambridge University Press.

Ceci, S. \& Roazzi, A. (1994). The effects of context on cognition: Postcards from Brazil. In R. J. Sternberg \& R. K. Wagner (Eds.), Mind in context: Interactionist perspectives on human intelligence (pp. 74-101). New York: Cambridge University Press.

Choo, C. (1998). The knowing organization: how organizations use information to construct meaning, create knowledge, and make decisions. New York: Oxford University Press.

Cimino, J. (1999). Development of expertise in medical practice. In Sternberg, R. \& Horvath, J. (Eds.). Tacit Knowledge in Professional Practice: Researcher and Practitioner Perspectives. Mahwah, NJ: Lawrence Erlbaum.

Claxton, C.S. \& Ralston,, \&. (1978). Learning styles: Their impact on teaching and administration, Washington dc: American Association for Higher Education.

Collins, H. (2001). Tacit knowledge, trust, and the Q of sapphire. Social Studies of Science, $31,1,71-85$.

Colonia-Willner, R. (1998). Practical intelligence at work: Relationship between aging and cognitive efficiency among managers in a bank environment. Psychology and Aging, $13,1,45-57$.

Cooper, R. \& Sawaf, A. (1996). Executive EQ: Emotional Intelligence in Leadership and Organizations. New York: Grossett/Putnam.

Cunningham, I., \& Dawes, G. (1997). Problematic premises, presumptions, presuppositions and practices in management education and training. In J. Burgoyne \& M. Reynolds (Eds.), Management Learning: Integrating perspectives in theory and practice. London: Sage Publications, pp. 110-126.

Curry, L. (1983). An organization of learning style theory and constructs. In L. Curry, Learning Style in Continuing Medical Education (pp115-131). Ottawa: Canadian Medical Association.

Curry, L. (2000). Review of learning style, studying approach, and instructional preference research in medical education. In R.J. Riding \& S.G. Rayner (Eds) International perspectives on individual differences. Stamford: Ablex Publishing.

Davenport, T. \& Prusak, L. (1998) Working Knowledge: How organizations manage What They Know. Boston, MA: Harvard Business School Press. 
Dervin B. (1992). From the mind's eye of the user: The Sense-Making qualitative-quantitative methodology. In Glazier J. \& Powell R. (Eds.). Qualitative Research in Information Management. Englewood, Colorado: Libraries Unlimited, Inc.

Dunn, R. \& Griggs, S.A. (2003). Synthesis of the Dunn and Dunn Learning-Style Model Research: who, what, when, where, and so what? New York: St John's University Press.

Ekpenyong, L.E. (1999). A Reformulation of the Theory of Experiential Learning Appropriate for Instruction in Formal Business Education. Journal of Vocational Education and Training, 51, 3.

Eraut, M. (1994). Developing Professional Knowledge and Competence. Falmer Press. London.

Fauziah Ismail. (1980). Training of civil servants in Malaysia. In Amara Raksasataya and Henrich Siedentopf, (eds), Asian Civil Services Technical Papers, vol. 4: Training in the Civil Service, Bonn: Konrad Adenauer Stiftung (Institute for International Partnership), and Kuala Lumpur: Asian and Pacific Development Administration Center.

Forsythe, G., Hedlund, J. Snook, S., Horvath, J., Williams, W., Bullis, R., Dennis, M., \& Sternberg, R. (1998). Construct Validation of Tacit Knowledge for Military Leadership. Paper presented at the Annual Meeting of the American Educational Research Association, San Diego, California, April 13-17, 1998. Available: http://www.aera.net/divisions/i/home/ForsythePaper.pdf

Fukami, C. (2007, forthcoming). Can wisdom be taught? In Eric H. Kessler and James R. Bailey (Eds.) Handbook of Organizational and Managerial Wisdom, Sage Publications; Thousand Oaks, CA.

Geiger, M., Boyle, E. \& Pinto, J. (1993). An Examination of Ipsative and Normative Versions of Kolb's Revised Learning Style Inventory. Educational and Psychological Measurement, 53, 717-726.

Gottfredson, L. S. (2003). Dissecting practical intelligence theory: Its claims and evidence. Intelligence, 3 (14), 343-397.

Hall, R. (1993). A framework for linking intangible resources and capabilities to sustainable competitive advantage. Strategic Management Journal, 14, 607-618.

Hatsopoulos, N. \& Hatsopoulos, G. (1999). The role of tacit knowledge in management. In Sternberg, R. \& Horvath, J. (Eds.). Tacit Knowledge in Professional Practice: Researcher and Practitioner Perspectives. Mahwah, NJ: Lawrence Erlbaum. 
Hayes, J. \& Allinson, C. W. (1996). The Implications of Learning Styles for Training and Development: A Discussion of the Matching Hypothesis: British Journal of Management, 7, 63-73.

Hedlund, J., Sternberg, R. \& Psotka, J. (2001). Identifying the Abilities Involved In the Acquisition of Tacit Knowledge, Leadership Research Interest Group, The George Washington University. Downloaded 21 Nov. 2002 from http://www.gwu.edu/ leader/downloads/TKAP_REPORT_Revised_7_31.doc Hempen, Joe (2002). Global Innovation. The Quality Management Journal, 9, 4, 77-79.

Herbig, B., Büssing, A., \& Ewert, T. (2001). The role of tacit knowledge in the work context of nursing. Journal of Advanced Nursing, 34, 5, 687-695.

Higgs, M. (2001). Is there a relationship between the Myers-Briggs type indicator and emotional intelligence? Journal of Managerial Psychology, 16, 7/8, 509-533.

Hudak, M.A. (1985). Review of Learning Style Inventory. In D.J. Keyser and R.C. Sweetlands (eds.), Test Critiques, vol. II, 402-410, Kansas City, Test Corporation of America.

Janik, A. (1988). Tacit knowledge, working life and scientific method. In Göranzon, B. \& Josefson, I. (Eds.). Knowledge, skill and artificial intelligence. London \& Berlin: Springer-Verlag.

Jarvis, P. (1987). Adult Learning in the Social Context. London: Croom Helm.

Jonassen, D. \& Grabowski, B. (1993). Handbook of Individual Differences, Learning, and Instruction. Lawrence Erlbaum Associated: Hillsdale, NJ.

Katz, N. (1990). Problem solving and time: Functions of learning style and teaching methods. Occupational Therapy Journal of Research, 10, 221-236.

Kayes, D.C. (2002). Experiential learning and its critics: Preserving the role of experience in management learning and education. Academy of Management Learning and Education, 1 (2), pp137 - 149.

Kenworthy-U'Ren, A.L., \& O'Peterson, T. (2005). Service learning and management education. Academy of Management Learning and Education, 4 (3), 272-277.

Kerr, M.R. (1991). An Analysis and Application of Tacit Knowledge to Managerial Selection. Unpublished doctoral dissertation, University of Waterloo, Waterloo, Ontario.

Klemp, G. \& McClelland, D. (1986). What characterizes intelligent functioning among senior managers? In Sternberg, R. \& Wagner, R. (Eds.). Practical intelligence: Nature and origins of competence in the everyday world. New York: Cambridge University Press. 
Kolb, D. (1981). Learning styles and disciplinery differences. In Chickering, A.W. and associates, The modern American College, San Fransisco: Jossey Bass.

Kolb, D. A. (1984). Experiential learning: experience as the source of learning development. Englewood Cliffs: Prentice-Hall.

Kolb, D. A. (1999a). Learning Style Inventory, version 3. TRG Hay/McBer, Training Resources Group. 116 Huntington Avenue, Boston, MA 02116, trg_mcber@haygroup.com.

Kolb, D. A. (1999b). Learning Style Inventory, version 3: Technical specifications. TRG Hay/McBer, Training Resources Group. 116 Huntington Avenue, Boston, MA 02116, trg_mcber@haygroup.com.

Kolb, D. A. \& Fry, R. (1975). Towards an applied theory of experiential learning. In Cooper, C. L. (Ed.). Theories of group processes. New York: John Wiley.

Kolb, A.Y., \& Kolb, D.A. (2005). Learning styles and learning spaces: Enhancing experiential learning in Higher Education. Academy of Management Learning and Education, 4, 2, 193-212.

Kolb, D.A., Boyatzis, R.E., \& Mainemelis, C. (2000). Experiential Learning Theory: Previous Research and New Directions. In R.J. Sternberg and L.F. Zhang (Eds.), Perspectives on cognition, learning, and thinking styles. NJ: Lawrence Erlbaum.

Leithwood, K., \& Steinbach, R. (1995). Expert problem solving: Evidence from school and district leaders. Albany: State University of New York Press.

Lubit, R. (2001). Tacit knowledge and knowledge management: the keys to sustainable competitive advantage. Organizational Dynamics, 29, 4, 164-178.

Mahmud, A. (2006). An empirical investigation of the nature of management development, with particular emphasis on the influence of learning styles on the level of accumulated managerial tacit knowledge in the Malaysian Public Sector. Unpublished $\mathrm{PhD}$ thesis, University of Hull, UK.

Mahmud, A., Armstrong, S.J., \& Zhu, Z. (2004). The influence of learning styles on knowledge acquisition in public sector management. Educational Psychology, 24, 4, 549-571.

Malek Shah bin Mohd Yusoff. (2003). Globalization and Human Resource Development in the Malaysian Public Service. Paper presented at the EROPA 19th General Assembly and Conference, 10 October, 2003, New Delhi, India.

Marchant, G. \& Robinson, J. (1999). Is knowing the tax code all it takes to be a tax expert? On the development of legal expertise. In Sternberg, R. \& Horvath, J. (Eds.). Tacit 
Knowledge in Professional Practice: Researcher and Practitioner Perspectives. Mahwah, NJ: Lawrence Erlbaum.

Melear, C.T. (1989). Cognitive processes in the Curry learning style framework as measured by the learning style profile and the Myers-Briggs Type Indicator among non majors in college biology. Unpublished Doctoral Dissertation, Ohio State University.

Merritt, S. L. \& Marshall, J. C. (1985). Reliability and construct validity of alternate forms of the Learning Styles Inventory. Educational and Psychological Measurement, 45, 931937.

Messick, S. (1976). Personality consistencies in cognition and creativity. In: S. Messick and Associates (eds) Individuality in Learning. San Fransisco, CA: Jossey Bass, 4-22.

Messick, S. (1984). The nature of cognitive styles: Problems and promise in educational practice, Educational Psychologist, 19, 2, 59-74.

Meyer, Heinz-Dieter (2003). The dia-logical nature of managerial knowledge-implications for the preparation of education leaders. Journal of Educational Administration, 41, 4/5, 455-470.

Minstrell, J. (1999). Expertise in teaching. In Sternberg, R. \& Horvath, J. (Eds.). Tacit Knowledge in Professional Practice: Researcher and Practitioner Perspectives. Mahwah, NJ: Lawrence Erlbaum.

Morgan, G. (1986). Images of Organizations. Newbury Park, CA: Sage Publications.

Murphy, G. \& Wright, J. (1984). Changes in conceptual structure with expertise: Differences between real-world experts and novices. Journal of experimental psychology: learning, memory and cognition, 10, 144-154.

Neisser, U. (1976). General, academic, and artificial intelligence. In Resnick, L. (Ed.). The nature of intelligence. Hillsdale, NJ: Erlbaum.

Nestor-Baker, N. (1999). Tacit knowledge in the superintendency: An exploratory analysis. (Doctoral dissertation, The Ohio State University). University Microfilms International Dissertation Services, AAT 9941397.

Nestor-Baker, N. \& Hoy, W. (2001). Tacit knowledge in school superintendents: its nature, meaning, and content. Educational Administration Quarterly, 37, 1, 86-129.

Nonaka, I. (1994). A dynamic theory of organizational knowledge creation. Organization Science, 5, 1, 14-37.

Nonaka, I. \& Takeuchi, H. (1995). The knowledge-creating company. Oxford: Oxford University Press.

Norusis, M.J. (1994). SPSS 6.1 Base System Users Guide; Part 2, SPSS Inc, Chicago, IL. 
Nulty, D. \& Barrett, M. (1996). Transitions in students' learning styles. Studies in Higher Education, 21, 2, 333-345.

Patel, V., Arocha, J. \& Kaufman, D. (1999). Expertise and tacit knowledge in medicine. In Sternberg, R. \& Horvath, J. (Eds.). Tacit Knowledge in Professional Practice: Researcher and Practitioner Perspectives. Mahwah, NJ: Lawrence Erlbaum.

Polanyi, M. (1966). The Tacit Dimension. London: Routledge \& Kegan Paul Ltd.

Prahalad, C. \& Hamel, G. (1990). The core competence of the corporation. Harvard Business Review, 68, 79-91.

Raelin, J. (1999). Preface to special issue on action research. Management Learning, V30, Iss 2, pp115-125

Reber, A. (1989). Implicit learning and tacit knowledge. Journal of Experimental Psychology: General, 118, 3, 219-235.

Reber, A. \& Lewis, S. (1977). Toward a theory of implicit learning: the analysis of the form and structure of a body of tacit knowledge. Cognition, 5, 333-361.

Reuber, A.R., Dyke, L.S., \& Fisher, E.M. (1990). Using a tacit knowledge methodology to define expertise, Proceedings of the 1990 ACM SIGBDP conference on Trends and directions in expert systems in Orlando, Florida. New York: ACM Press.

Robey, D. \& Taggart, W. (1981). Measuring managers' minds: The assessment of style in human information processing. Academy of Management Review, 6, 375 - 383.

Romero, J.E., Tepper, B.J. \& Tetrault, L.A. (1992). Development and Validation of New Scales to Measure Kolb's (1985) Learning Style Dimensions. Educational and Psychological Measurement, 52, 1, 171-180.

Rush, M. G. \& Moore, D. M. (1991). Effects of Restructuring Training and Cognitive Style. Educational Psychology, 11, 3 \& 4, 309-321.

Sadler-Smith, Eugene (2001). A Reply to Reynolds’s Critique of Learning Style. Management Learning, 32, 3, 291-304.

Schön, D. (1983). The reflective practitioner: How professionals think in action. New York: Basic Books, Inc.

Schön, D. (1991). The reflective practitioner. Aldershot: Arena Books.

Scribner, S. (1986). Thinking in action: some characteristics of practical thought. In Sternberg, R. \& Wagner, R. (Eds.). Practical intelligence: Nature and origins of competence in the everyday world. New York: Cambridge University Press.

Sein, M.K., Bostrom, R.P. (1989). Individual differences and the training of novice users. Human Computer Interaction, 4, 197-229. 
Serpell, R. (2000). Intelligence and culture. In R. J. Sternberg (Ed.), Handbook of Intelligence, (pp. 549-580). New York: Cambridge University Press.

Simon, H. (1973). The structure of ill-structured problems. Artificial Intelligence, 4, 181-201.

Sternberg, R. (1985). Beyond IQ: A triarchic theory of human intelligence. New York: Cambridge University Press.

Sternberg, R., Forsythe, G., Hedlund, J., Horvath, J., Wagner, R., Williams, W., Snook, S., \& Grigorenko, E. (2000). Practical intelligence in everyday life. New York: Cambridge University Press.

Sternberg, R. \& Grigorenko, E. (2001a). Practical Intelligence and the Principal. Publication Series No. 2, Yale University. Available: http://www.temple.edu/lss/pdf/publications/pubs2001-2.pdf

Sternberg R. \& Grigorenko, E. (2001b). A Capsule History of Theory and Research on Styles. In Sternberg, R. \& Zhang, L. (Eds.). Perspectives on Thinking, Learning, and Cognitive Styles. Mahwah, NJ: Lawrence Erlbaum Associates.

Sternberg, R. \& Horvath, J. (eds) (1999). Tacit Knowledge in Professional Practice: Researcher and Practitioner Perspectives. Mahwah, NJ: Lawrence Erlbaum.

Sternberg, R. \& Wagner, R. (1993). The g-ocentric view of intelligence and job performance is wrong. Current Directions in Psychological Science, 2, 1-4.

Sternberg, R. \& Wagner, R. (Eds.). (1986). Practical intelligence: Nature and origins of competence in the everyday world. New York: Cambridge University Press.

Sternberg, R., Wagner, R. \& Okagaki, L. (1993). Practical intelligence: The nature and role of tacit knowledge in work and school. In Reese, H. and Puckett, J. (Eds.), Mechanisms of everyday cognition. Hillsdale, NJ: Erlbaum.

Sternberg, R., Wagner, R., Williams, W. \& Horvath, J. (1995). Testing common sense American psychologist, 50, 11, 912-927.

Tan, H. \& Libby, R. (1997). Tacit managerial versus technical knowledge as determinants of adult expertise in the field. Journal of accounting research, 35, 1, 97-113.

Tulving, E. (1972). Episodic and Semantic Memory. In Tulving, E. \& Donaldson, W. (Eds.). Organization of Memory. New York: Academic Press.

von Krogh, G. \& Roos, J. (1995). Organizational epistimology. London: Macmillan.

Vondrell, J.H., \& Sweeney, J.M. (1989). Independent study: using learning style assessment to predict student success. Continuing Higher Education, Winter, 5-7.

Wagner, R. (1987). Tacit knowledge in everyday intelligent behaviour. Journal of Personality and Social Psychology, 52, 6, 1236-1247. 
Wagner, R. K. \& Sternberg, R. J. (1985). Practical intelligence in real-world pursuits: The role of tacit knowledge. Journal of Personality and Social Psychology, 48, 436-458.

Wagner, R. K. \& Sternberg, R. J. (1986). Tacit knowledge and intelligence in the everyday world. In Sternberg, R. \& Wagner, R. (Eds.). Practical intelligence: Nature and origins of competence in the everyday world. New York: Cambridge University Press.

Wagner, R. K. \& Sternberg, R. J. (1987). Tacit knowledge in managerial success. Journal of Business and Psychology, 1, 4, 301-312.

Wagner, R., Sujan, H., Sujan, M., Sternberg, R. \& Raashotte, C. (1999). Tacit knowledge in sales. In Sternberg, R. \& Horvath, J. (Eds.). Tacit Knowledge in Professional Practice: Researcher and Practitioner Perspectives. Mahwah, NJ: Lawrence Erlbaum.

Williams, W. (1991). Tacit knowledge and the successful executive (Doctoral dissertation, Yale University, 1991). University Microfilms International Dissertation Services, AAT9136207. 


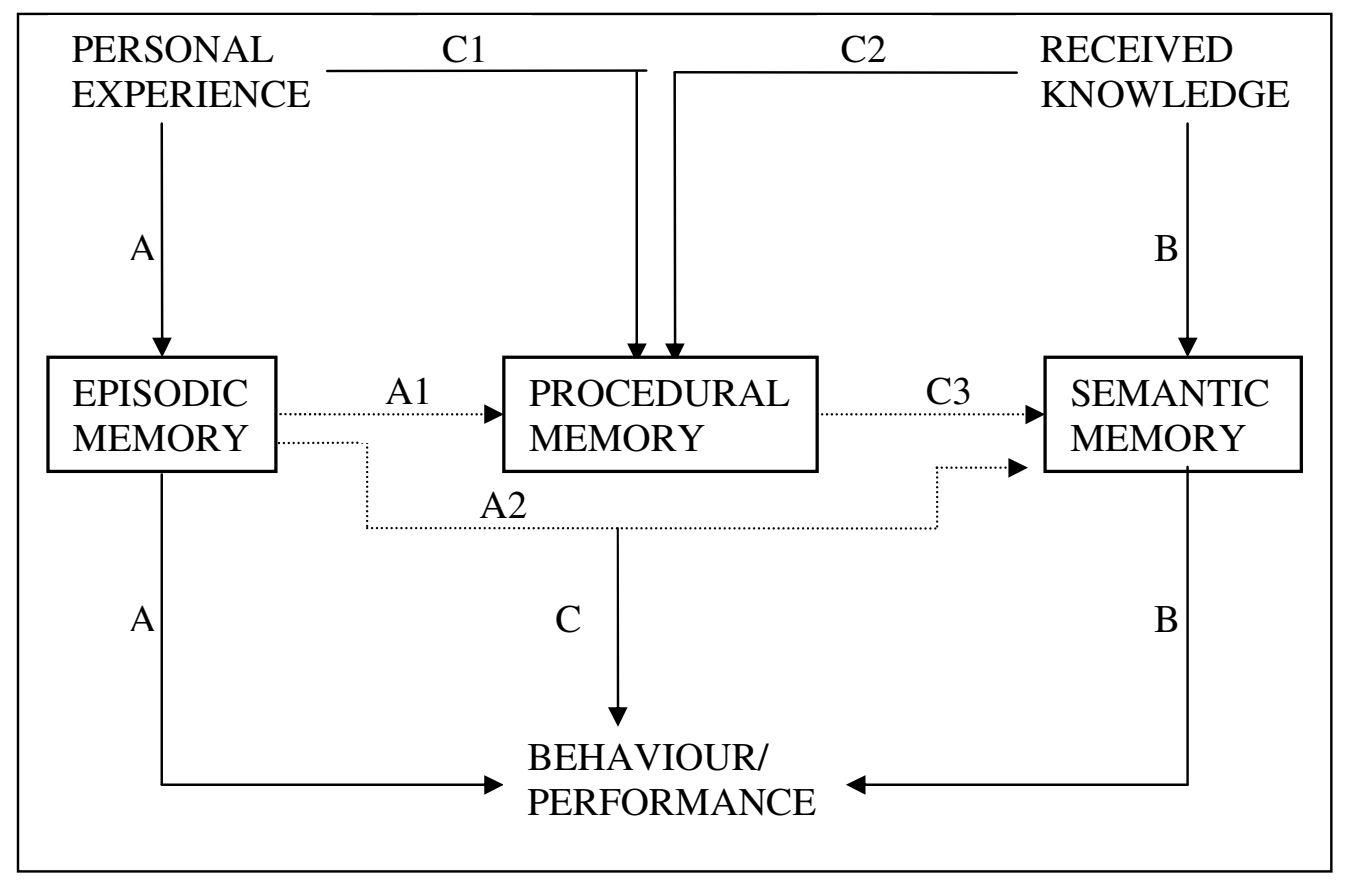

Figure 1: Memory structures and knowledge acquisition pathways in a cognitive model of tacit knowledge. (Source: Sternberg et al., 2000. Practical Intelligence in Everyday Life, p.114). 


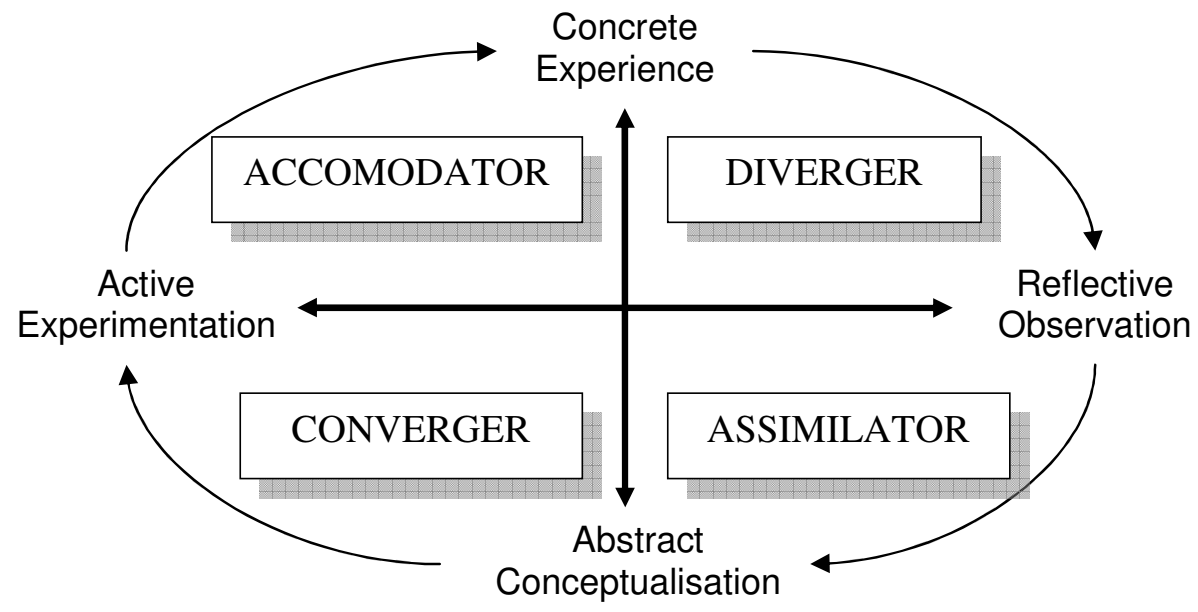

Figure 2: Kolb's Learning Styles (Adapted from Kolb et al., 1999). 
$\underline{\text { Table } 1}$

Years of experience for the three sample groups

\begin{tabular}{lcccc}
\hline \multicolumn{1}{c}{ Group } & $\underline{\mathbf{n}}$ & $\underline{\text { Range }}$ & $\underline{\text { Mean }}$ & $\underline{\underline{\text { Standard }}}$ \\
& 113 & $0.3-0.9$ & $\underline{\text { Deviation }}$ \\
\hline Novice & 206 & $1-31.6$ & 0.55 & 0.1 \\
Typical & 37 & $6.2-24.6$ & 9.42 & 8.5 \\
Successful & & 17.20 & 5.1 \\
\hline
\end{tabular}


Table 2

Internal consistency reliability estimates for the two inventories

\begin{tabular}{lrcc}
\hline Scales & & $\boldsymbol{N}$ (cases) & $\boldsymbol{\alpha}$ - coefficient \\
\hline TKIM & & 356 & .713 \\
& self & & .52 \\
& task & & .58 \\
& others & & .51 \\
& & & \\
LSI & & 290 & \\
& & & .85 \\
& CE & & .87 \\
& AC & & .88 \\
& AE & & .82 \\
\hline
\end{tabular}


Table 3

Comparisons of LAMTK scores for novice, typical and successful groups of employees within the Malaysian Public sector using one-way analysis of variance

\begin{tabular}{clccccc}
\hline Group & LAMTK & $\mathbf{n}$ & Mean & $\begin{array}{c}\text { Std. } \\
\text { Deviation }\end{array}$ & $\boldsymbol{d} f$ & $\mathbf{F}$ \\
\hline 1 & Novice & 113 & $.944^{3}$ & .190 & 2 & $5.37^{* *}$ \\
2 & Typical & 206 & .893 & .111 & \\
3 & Successful & 37 & $.882^{1}$ & .125 & \\
\hline
\end{tabular}

$* * \mathrm{p}=0.005$

Superscript to a mean refers to a group whose mean is significantly different (Duncan multiple range test) 
Table 4

\section{Two-way ANOVA of LAMTK by Learning Styles and Managerial}

\section{Context}

\begin{tabular}{|l|l|c|c|c|c|}
\hline \multicolumn{2}{|l|}{} & df & Mean Square & F & Sig. \\
\hline & (Combined) & 7 & .071 & 3.52 & .001 \\
\hline & Learning Styles & 3 & .091 & 4.5 & .00 \\
\hline & Managerial Context & 1 & .005 & 0.24 & .63 \\
\hline $\begin{array}{l}\text { 2-Way } \\
\text { Interactions }\end{array}$ & $\begin{array}{l}\text { Learning Styles * } \\
\text { Managerial }\end{array}$ & 3 & .058 & $\begin{array}{c}2.8 \\
5\end{array}$ & $\begin{array}{c}.03 \\
7\end{array}$ \\
\hline
\end{tabular}


$\underline{\text { Table } 5}$

Comparisons of LAMTK for the four learning styles of subjects working in a

management context using one-way analysis of variance

\begin{tabular}{clccccc}
\hline Group & $\begin{array}{c}\text { Learning } \\
\text { Styles }\end{array}$ & $\mathbf{n}$ & mean & $\begin{array}{c}\text { Standard } \\
\text { deviation }\end{array}$ & $\boldsymbol{d} f$ & $\mathbf{F}$ \\
\hline 1 & Accommodator & 43 & $0.869^{2,3}$ & .079 & 3 & $4.21^{* * *}$ \\
2 & Diverger & 47 & $0.969^{1,4}$ & .214 & & \\
3 & Assimilator & 46 & $0.944^{1}$ & .182 & & \\
4 & Converger & 55 & $0.883^{2}$ & .132 & & \\
\hline
\end{tabular}

$* * \mathrm{p}=0.007$

Superscript to a mean refers to a group whose mean is significantly different (Duncan multiple range test) 
$\underline{\text { Table } 6}$

Comparison of LAMTK for Kolb's four learning abilities using one-way analysis of variance

\begin{tabular}{ccccccc}
\hline Group & Quartiles & $\mathbf{n}$ & Mean & $\begin{array}{c}\text { Std. } \\
\text { Deviation }\end{array}$ & $\boldsymbol{d} \boldsymbol{f}$ & F \\
\hline 1 & Upper Most & 30 & $0.894^{3}$ & .120 & 2 & $8.45^{* * *}$ \\
2 & Middle & 264 & $0.902^{3}$ & .129 & & \\
3 & Lowest & 25 & $1.023^{1,2}$ & .263 & & \\
& Total & 319 & 0.911 & .146 & & \\
& & & &
\end{tabular}

$* * * \mathrm{p}=0.000$

Superscript to a mean refers to a group whose mean is significantly different (Duncan multiple range test) 


\section{APPENDIX A}

\section{The Tacit Knowledge Inventory for Managers (TKIM)}

Wagner and Sternberg (1985) developed the Tacit Knowledge Inventory for Managers (TKIM) by using the critical incident technique. According to Forsythe et al.(1998) this is defined by focusing on three core categories of managing self (maximizing self-performance and productivity), managing others (working with, and directing others), and managing career (establishing and enhancing self- reputation). It defined the scope of tacit knowledge based on the content of a situation. Whilst an instrument such as this can never access the entire spectrum of managerial tacit knowledge, it does nevertheless define important aspects against which the learning associated with its acquisition can be explored.

The scenarios depicted in the TKIM are designed to elicit different responses from different individuals. Theoretically, successful managers are expected to respond differently to novices due to the content and organization of their tacit knowledge (Wagner et al., 1999). The scenarios presented in the TKIM are work-related situations, each followed by a series of items that are relevant to handling that situation. The instructions given for completing the TKIM requested that respondents briefly scan all of the items and then rate the quality of each item on the 1 to 7 scale provided. Instructions to respondents also stressed that there were no "correct" answers, only different ways to respond to each situation. A sample scenario from the TKIM is presented for information below.

\section{Situation}

You and a co-worker are jointly responsible for completing a report on a new project by the end of the week. You are uneasy about this assignment because the co-worker has a reputation for not meeting deadlines. The problem does not appear to be lack of effort. Rather, he seems to lack certain organizational skills necessary to meet a deadline and is also quite a perfectionist. As a result, too much time is wasted coming up with the "perfect" idea, project, or report. 
Your goal is to produce the best possible report by the deadline at the end of the week. Rate the quality of the following strategies for meeting your goal on a 1- to 7-point scale.

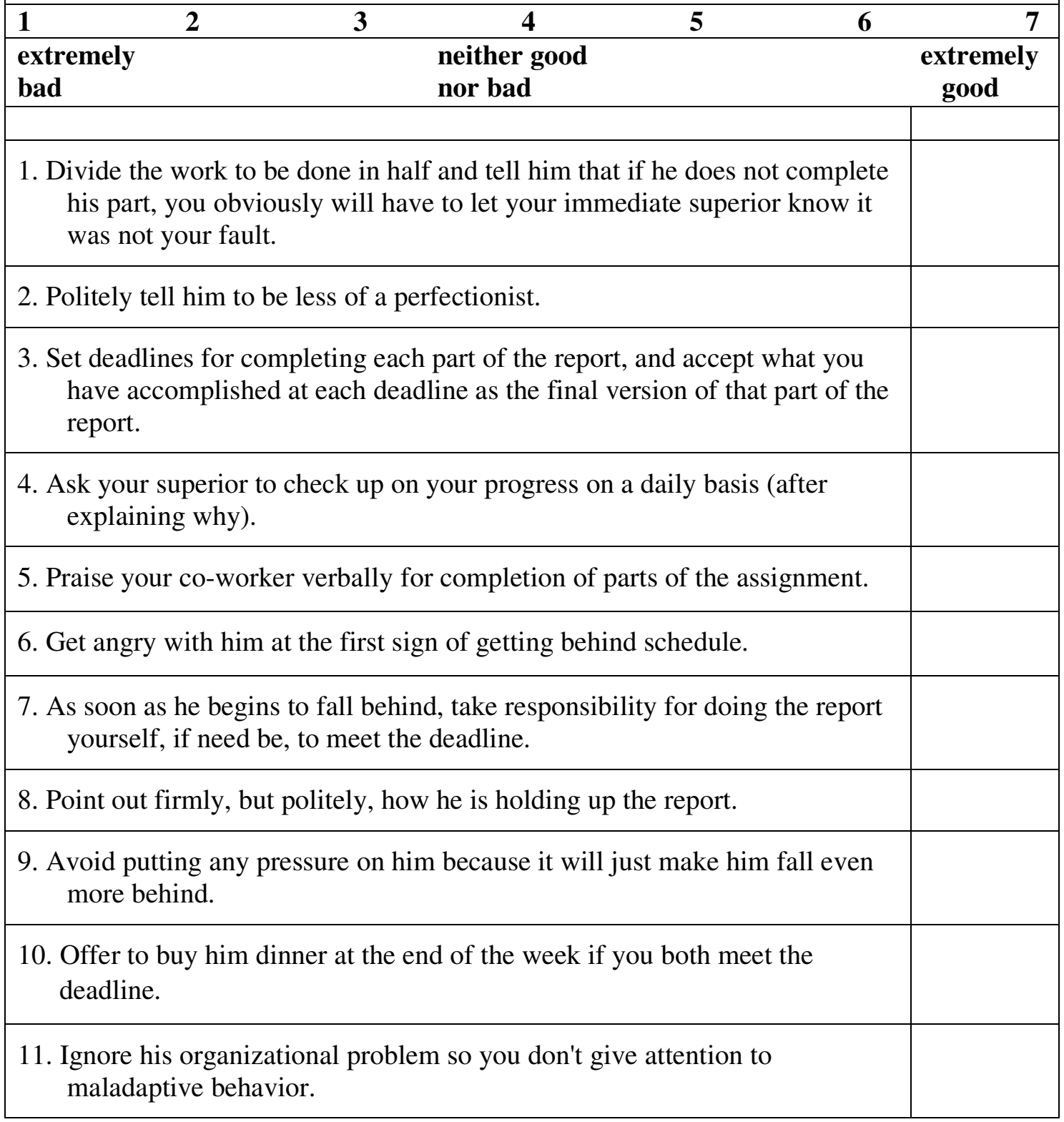

\section{Scoring the TKIM}

The scoring method employed by Wagner (1987) has been recognised for its ability to allow for meaningful comparisons between groups (Sternberg et al., 1995). Before scoring began, subjects' ratings were first transformed after taking into account Wagner's (1987) observation 
that tacit knowledge scores generated by the prototype method are affected by individual differences in subjects' use of the entire scale. He argued that because scores are based on deviation from an expert profile, they would vary with the extent to which a subject used the entire rating scale. He therefore suggested that the raw data on the tacit knowledge inventory be transformed by "standardizing the standard deviation of ratings across response items for subjects to the common value of 1.5 " (Op-cit. p. 1241). Every entry was therefore transformed to a standardized standard deviation of 1.5 in the present study using the formula:

\section{$\left(\left(\left(\mathrm{x}_{\mathrm{ij}}-\mathrm{x}_{\mathrm{i}}\right) / \mathrm{sd}_{\mathrm{i}}\right) \times 1.5\right)$}

where, $\quad \mathrm{i}=1-356 ; \mathrm{j}=1-81 ; \mathrm{x}_{\mathrm{i}}=$ mean across each subject's response items; $\mathrm{sd}_{\mathrm{i}}=$ standard deviation across each subject's response items.

Menkes (2002) described the TKIM's scoring instruction in the following detail. First, test administrators are instructed to develop their own expert/successful group. The mean ratings for each item in the instrument are calculated for the successful group in order to form a successful manager's profile. Then, participant's scores on the TKIM are derived by subtracting their answer for each item from the successful profile for that item. This generates difference scores between the participants and the successful profile (Wagner and Sternberg, 1990) that can produce either positive or negative values.

Some previous authors (Colonia-Willner, 1998; Wagner, 1987) have chosen to square these difference scores to remove the polarity, whilst others have argued that squaring tends to inflate the value and this affects further calculations (Kerr, 1991). Citing Cronbach \& Gleser (1953), Kerr (1991) argued for the use of absolute values for studies such as those that use expert-novice comparisons, and this approach has been adopted in the present study.

Values for each of the work-related situations in the inventory are then summated in order to arrive at a score for each of the three contexts of managing self, managing task, and managing others. Summating the scores for each of these sub-scales yields a total score for tacit knowledge. Colonia-Willner's (1998) approach was then adopted where the summated scores for each situation were divided by the number of items representing that situation, in order to provide an average value. Averaging was necessary to facilitate meaningful comparisons between the three contexts because they were not made up of the same number of items. 


\section{APPENDIX B}

\section{Scoring Regime for Geiger's Normative version of the Learning Style Inventory}

Kolb's original Learning Styles Inventory was used by Geiger et al (1993) to produce a randomly ordered 48-item questionnaire using 7-point Likert scales as discussed on page $\mathrm{xx}$ of this article. When scoring each item, a ' 1 ' is given to a response indicating 'Not like me' and a ' 7 ' to a response indicating 'Very much like me'.

The four basic learning modes are 'Activist' with an orientation towards Concrete Experience (CE), 'Reflector' with an orientation towards Reflective Observation (RO), 'Theorist' with an orientation towards Abstract Conceptualisation (AC), and 'Pragmatist' with an orientation towards Active Experimentation (AE). Raw scores for each of these modes are determined by summating scores from the questionnaire items as follows:

Active Experimentation (AE) - items 2, 5, 7, 8, 19, 20, 24, 28, 30, 32, 35, 42.

Reflective Observation (RO) - items 11, 13, 15, 22, 25, 29, 31, 33, 45, 46, 47, 48.

Abstract Conceptualisation (AC) - items 1, 3, 4, 10, 12, 16, 27, 34, 36, 37, 38, 43.

Concrete Experience (CE) - items 6, 9, 14, 17, 18, 21, 23, 26, 39, 40, 41, 44.

A subject's position on the Active Experimentation - Reflective Observation dimension of Kolb's model depicted in Figure 2 is determined by subtracting RO scores from AE scores. Similarly, a subject's position on the Abstract Conceptualisation - Concrete Experience dimension is determined by subtracting $\mathrm{CE}$ scores from $\mathrm{AC}$ scores. The intersection between the two modes on each dimension are determined by taking the $50^{\text {th }}$ percentile score.

Assuming ' $x$ ' to be the $50^{\text {th }}$ percentile score for the AE-RO dimension and ' $y$ ' to be the $50^{\text {th }}$ percentile score for the AC-CE dimension, then the dominant learning style for each subject is determined as follows:

$\begin{array}{llll}\text { Accommodator } & \text { if } \mathrm{AC}-\mathrm{CE}<\mathrm{y} & \text { and } & \mathrm{AE}-\mathrm{RO}>\mathrm{x} \\ \text { Diverger } & \text { if } \mathrm{AC}-\mathrm{CE}<\mathrm{y} & \text { and } & \mathrm{AE}-\mathrm{RO}<=\mathrm{x} \\ \text { Assimilator } & \text { if } \mathrm{AC}-\mathrm{CE}>=\mathrm{y} & \text { and } & \mathrm{AE}-\mathrm{RO}<=\mathrm{x} \\ \text { Converger } & \text { if } \mathrm{AC}-\mathrm{CE}>=\mathrm{y} & \text { and } & \mathrm{AE}-\mathrm{RO}>\mathrm{x}\end{array}$


For the purpose of group comparisons, subjects whose dominant learning styles were found to be Accommodators (emphasis on $\mathrm{CE}$ and $\mathrm{AE}$ ) were formed into one group, Divergers (emphasis on $\mathrm{CE}$ and RO) into a second group, Assimilators (emphasis on AC and RO) into a third group, and Convergers (emphasis on AC and AE) into a fourth. 


\section{APPENDIX C}

Univariate statistics and Pearson correlations among demographic variables, TKIM, and LSI scores $(\mathrm{N}=319)$

\begin{tabular}{|c|c|c|c|c|c|c|c|c|c|c|c|c|c|c|c|c|c|}
\hline Item & & Mean & SD & 1 & 2 & 3 & 4 & 5 & 6 & 7 & 8 & 9 & 10 & 11 & 12 & 13 & 14 \\
\hline 1 & Age & 31.9 & 8.7 & - & & & & & & & & & & & & & \\
\hline 2 & Number of staff & 13.5 & 37.3 & $.14 *$ & - & & & & & & & & & & & & \\
\hline 3 & Years experience & 6.28 & 8 & $.93 * *$ & .11 & - & & & & & & & & & & & \\
\hline 4 & Educational level & 3.02 & .65 & $-.13 *$ & .02 & -.04 & - & & & & & & & & & & \\
\hline 5 & LAMTK: & .91 & .15 & -.04 & -.02 & -.06 & $-.15 * *$ & - & & & & & & & & & \\
\hline 6 & task & .87 & .19 & -.04 & -.06 & -.05 & $.15 * *$ & $.8 * *$ & - & & & & & & & & \\
\hline 7 & self & .87 & .21 & -.05 & -.01 & -.03 & $.13^{*}$ & $.67 * *$ & $.43 * *$ & - & & & & & & & \\
\hline 8 & other & .98 & .19 & -.02 & .03 & -.06 & .06 & $.74 * *$ & $.33 * *$ & $.22 * *$ & - & & & & & & \\
\hline 9 & $\mathrm{CE}$ & 4.80 & .78 & -.02 & -.11 & .00 & -.06 & -.04 & .02 & -.04 & -.06 & - & & & & & \\
\hline 10 & $\mathrm{AC}$ & 5.39 & .68 & .03 & -.11 & .04 & -.06 & $-.19 * *$ & $-.2 * *$ & $-.19 * *$ & -.05 & $.55^{* * *}$ & - & & & & \\
\hline 11 & $\mathrm{AE}$ & 5.46 & .73 & .04 & -.09 & .06 & .04 & $-.24 * *$ & $-.23 * *$ & $-.18 * *$ & $-.13 *$ & $.60^{* *}$ & $.71 * *$ & - & & & \\
\hline 12 & RO & 5.19 & .68 & -.05 & $-.15^{*}$ & -.01 & -.06 & $-.18 * *$ & $-.13 *$ & $-.15 * *$ & $-.12 *$ & $.61 * *$ & $.68 * *$ & $.60 * *$ & - & & \\
\hline 13 & Sum LSI scores & & & -.00 & $-.14 *$ & .03 & -.04 & $-.18 * *$ & $-.15 * *$ & $-.16 * *$ & .11 & $.83 * *$ & $.86 * *$ & $.86 * *$ & $.85 * *$ & -.09 & .08 \\
\hline
\end{tabular}

Notes Significance (two-tailed): **p $<0.01, * p<0.05$ 